\title{
A INTERPRETAÇÃO DOS PRECEDENTES JUDICIAIS E OS DEVERES DE UNIFORMIZAÇÃO, ESTABILIDADE, INTEGRIDADE E COERÊNCIA DA JURISPRUDÊNCIA PREVISTOS NO ART. 926 DO CÓDIGO DE PROCESSO CIVIL
}

THE INTERPRETATION OF JUDICIAL PRECEDENTS AND THE DUTIES OF THE UNIFORMIZATION, STABILITY, INTEGRITY AND COHERENCE OF THE JURISPRUDENCE PROVIDED FOR IN ART. 926 OF THE CODE OF CIVIL PROCEDURE

André Soares Azevedo BRANCO'

ISSUE DOI: $10.21207 / 1983.4225 .853$

\begin{abstract}
RESUMO
Este artigo examina a questão da interpretação jurídica e a sua importância para um sistema de precedentes judiciais criador de normas jurídicas gerais e futuras, dando ênfase aos deveres impostos pelo art. 926 do Código de Processo Civil.

Palavras-chave: Precedentes Judiciais. Interpretação Jurídica. Art. 926 do Código de Processo Civil.
\end{abstract}

\section{ABSTRACT}

This article examines the question of legal interpretation and its importance for a system of judicial precedents that creates general and future legal norms, emphasizing the duties imposed by art. 926 of the Code of Civil Procedure.

\footnotetext{
${ }^{1}$ Especialista em Direito Processual Civil e Direito Individual e Processual do Trabalho pela Faculdade de Direito de Vitória (FDV), e em Direito Penal Econômico e Europeu pela Faculdade de Direito da Universidade de Coimbra (Portugal). Graduado em direito pela Faculdade de Direito de Vitória (FDV). Advogado. http://lattes.cnpq.br/7198802280025765
} 
Keywords: Judicial precedentes. Legal interpretation. Art. 926 of the code of civil procedure.

\section{INTRODUÇÃO}

Nos tempos atuais observa-se, sem qualquer distinção outrora existente da sua vinculação aos sistemas jurídicos de tradição da common law, que os precedentes ocupam cada vez mais espaço e são cada vez mais utilizados no sistema jurídico nacional, de tradição civilista.

Nesse sentido, dentre as maiores inovações trazidas pelo Código de Processo Civil de 2015 ao sistema jurídico brasileiro, encontra-se a positivação da figura dos precedentes judiciais.

E é dentro desse escopo, ainda carente de amadurecimento e de uma teoria própria, que se situa o presente trabalho, que tenta, em linhas gerais, explorar a questão da interpretação judicial dos precedentes judiciais e a sua importância para a sua construção e aplicação de uma teoria.

Com o objetivo de cumprir o proposto, foi o presente artigo dividido em três partes, iniciando a primeira delas com o instituto dos precedentes judiciais, a partir do qual faremos uma breve análise da sua teoria no sistema da common law e civil law, para após abordar o seu conceito, elementos e função no sistema jurídico.

Em seguida, é tratada a questão da interpretação no direito, com atenção especial a distinção entre texto e norma, o movimento que vai da sua prévia determinação à sua dupla indeterminação, bem como as teorias correspondentes a cada um desses momentos.

Por último, é analisado o disposto no art. 926 do Código de Processo Civil, que estabeleceu no sistema jurídico brasileiro normas gerais sobre precedentes, introduzindo/positivando a regra do stare decisis através da determinação da uniformização da jurisprudência dos tribunais, que tem o dever de mantê-la estável, integra e coerente.

\section{DO PRECEDENTE JUDICIAL}

2.1. DO CONCEITO DE PRECEDENTE JUDICIAL E SEUS ELEMENTOS (STARE DECISIS, RATIO DECIDENDI E OBITER DICTUM) 
Feita uma breve análise sobre os precentes judiciais nos países de tradição do common law e de civil law, mostra-se neste ponto fundamental apresentar um conceito do que são eles

Tal tarefa, contudo, mostra-se dificultosa, diante dos diversos estudos sobre o tema, muitas vezes calcados em autores de tradições jurídicofilosófico-ideológicas distintas.

No dicionário oxford, precedente é definido como "uma instância ou caso anterior que é, ou pode ser tomado como um exemplo de regra para casos subseqüientes, ou pelo qual algum ato similar ou ato ou circunstâncias similares podem ser apoiados ou justificados, significando, no campo judicial, orientação ou autoridade das decisões passadas para casos futuros. Apenas decisões como estabelecer uma nova regra ou princípio são chamadas de precedentes. É a atribuição de autoridade que torna uma decisão judicial um precedente judicial."

Para os fins do presente trabalho, adotaremos como conceito de precedente judicial o apresentado por Hermes Zaneti Jr, que assim os define: "Os precedentes judiciais, como entendemos nesse trabalho, consistem no resultado da densificação de normas estabelecidas a partir da compreensão de um caso e suas circunstâncias fáticas e jurídicas."

Ou seja, são os precedentes, em outras palavras, decisões anteriores que funcionaram como modelos para decisões posteriores.

Fixado o conceito de precedente judicial, necessário ainda a fixação dos seus elementos fundamentais: stare decisis, ratio decidendi e obiter dictum.

A expressão stare decisis, redução da expressão latina stare decisis et non quieta movere, traduz-se, segundo Sabrina Nasser de Carvalho ${ }^{3}$, como "mantenha-se a decisão e não se moleste o que foi decidido", em direito o seu significado relacionado ao respeito dos tribunais as suas

\footnotetext{
${ }^{2}$ ZANETI JR., Hermes. O valor vinculante dos Precedentes: teoria dos precedentes normativos formalmente vinculantes. $3^{\mathrm{a}}$ ed. Salvador: JusPODIVM, 2017. P. 328.

${ }^{3}$ CARVALHO, Sabrina Nasser de. Decisões paradigmáticas e dever de fundamentação: técnica para formação e aplicação dos precedentes. Revista de Processo. São Paulo, Revista dos Tribunais, vol. 40, n. 249, 2015. P. 02.

${ }^{4}$ A tradução da expressão mostra-se diferente na doutrina, muito embora o significado geral seja equivalente. Divergindo da tradução apresentada: MELLO, Patrícia Perrone Campos. Precedentes: o desenvolvimento judicial do direito no constitucionalismo contemporâneo. Rio de Janeiro: Editora Renovar, 2008. P. 116: "A expressão stare decisis deriva da frase latina: stare decisis et non quieta movere, que significa: "deixar quieto o que já foi decidido e não alterá-lo"; ZANETI JR, Hermes. Op. Cit. P. 335: "stare decisis é uma expressão latina que significa, literalmente, "concordar com ou aderir a casos já decididos".
} 
próprias decisões (que ficam vinculados tanto em nível horizontal quanto em nível vertical $)^{5}$.

Com relação a ratio decidendi (ou holding ${ }^{6}$ ), o seu conceito sempre foi objeto de muita discussão pela doutrina ao longo do tempo.

De uma forma ampla, assim como o fez Sabrina Nasser de Carvalho $^{7}$, podemos dizer cuida a ratio decidendi da tese ou princípio contido na decisão que irá se projetar aos casos futuros similares, regulamentandoos.

Ocorre que em razão das dificuldades encontradas para a extração dos precedentes, foram ao longo do tempo desenvolvidos divesos métodos com o objetivo de tentar auxiliar na sua identificação, dentre os quais podemos citar, como principais, os métodos de Eugene Wambaugh, de Herman Oliphant, e de Arthur Goodhart e Julius Stone. ${ }^{8}$

Já o obiter dictum, diferentemente da ratio decidendi, seriam a parte não vinculante da decisão, aquelas manifestações não necessárias a solução do caso, tendo, por essa razão, tão somente força persuassiva. ${ }^{9}$

Ou seja, corresponde a ratio decidendi a parte vinculante da decisão judicial, correspondento o obiter dictum a sua parte não vinculante.

\subsection{DA DISTINÇÃO ENTRE PRECEDENTE, JURISPRUDÊNCIA E SÚMULA}

\footnotetext{
${ }^{5}$ Entende-se a vinculação horizontal como o dever do próprio tribunal e seus órgãos em seguir os próprios precedentes, enquanto que na vinculação vertical figura o dever dos tribunais inferiores em seguir os precedentes estabelecidos pelos a eles superiores. ZANETI JR, Hermes. Op. Cit. P. 332: "Por vinculação horizontal deve-se entender a vinculação do próprio tribunal e dos seus órgãos de decisão aos seus próprios precedentes (...). Por vinculação vertical entendemos a vinculação aos precedentes de hierarquia institucional superior, ou seja, os tribunais e juízes de hierarquia institucional inferior estão obrigados a seguir as determinações dos órgãos de revisão (...).”

${ }^{6} \mathrm{Ibid}, \mathrm{p}$. 328. Não existe identidade absoluta entre ratio decidendi e holding, se referindo ambos a parte vinculante da decisão, com a diferença que a expressão ratio decidendi é normalmente utilizada na Inglaterra, enquanto holding é normalmente utilizada nos Estados Unidos.

${ }^{7}$ CARVALHO, Sabrina Nasser de. Op. Cit. P. 03.

${ }^{8} \mathrm{Ibid}$, p. 17: "A doutrina destaca três métodos de identificação das razões de decidir. O primeiro, teoria de Wambaugh, a ratio é determinada pela inversão do sentido da proposição do julgado: se a alteração implicar modificação do resultado da decisão, ela pode ser considerada como razão de decidir. A segunda, trata-se da teoria de Herman Oliphant, que perfilha o entendimento de que a ratio revela-se nos fatos específicos, pois seriam estes que trariam a previsibilidade da decisão e não as razões jurídicas. A terceira, teoria de Goodhart, preconiza-se no conceito de ratio decidendi baseada nos fatos substanciais utilizados pelo órgão julgador no julgamento e na conclusão jurídica advindas destes fatos."

${ }^{9}$ MELLO, Patrícia Perrone Campos. Op. Cit. p. 125.
} 
Superadas as premissas iniciais apresentadas, resta fundamental distinguir os termos precedente, jurisprudência e súmula.

Segundo nos ensina Michele Taruffo ${ }^{10}$, existe entre os termos duas formas de distinção, uma de caráter quantitativo e outra de caráter qualitativo.

No que diz respeito a sua distinção quantitativa, de forma geral, o precedente refere-se a uma única decisão particular, enquanto que a jurisprudência refere-se a várias decisões relativas a diversos casos concretos.

Já na distinção qualitativa, decorrência da distinção quantitativa, apresenta-se o precedente como uma regra universalizável aplicável ao caso futuro, enquanto que a jurisprudência serve tão somente como direção ao caso futuro, faltando nela a análise comparativa dos fatos.

Já as súmulas, segundo Daniel Mitidiero"1, "são enunciados que visam a retratar de modo simples e direto os precedentes. Em uma palavra: são extratos. Súmulas, portanto, são enunciados que visam retratar precedentes, alocando-se em um nível acima do nível do precedente."

\subsection{DA FUNÇÃO DOS PROCEDENTES JUDICIAIS}

Fixado o conceito de precedente judicial, identificados os seus elementos e feita a diferenciação entre os termos correlacionados, far-se-á um breve exame das suas principais funções nas duas principais tradições jurídicas - common law e civil law -, tratando posteriormente das suas funções no sistema jurídico nacional.

Enquanto nos países de common law as decisões judiciais situamse no centro do sistema, como elemento irradiador de normas, com as leis possuindo tão somente caráter secundário, nos países de tradição civilistica a lógica se inverte, cabendo à lei a manifestação do direito, com as decisões judiciais possuindo tão somente caráter secundário.

Portanto, como dito, as diferenças existem, já se iniciando na função apresentadas pelos precedentes em cada uma das tradições jurídicas.

\footnotetext{
${ }^{10}$ TARUFFO, Michele. Precedente e jurisprudência. Trad. Chiara de Teffé. Civilistica.com. Rio de Janeiro, a. 3, n. 2, jul.-dez./2014. Disponível em: http://civilistica.com/precedente-e-jurisprudencia/. p. 03/06.

${ }^{11}$ Ibid, p. 93.
} 
Neste sentido, é precisa Sabrina Nasser de Carvalho ${ }^{12}$, ao afirmar que "no civil law, os precedentes exercem função eminentemente interpretativa e não criativa do direito. Como acima já afirmado, os precedentes se prestam a aclarar o sentido de uma norma posta. De outro vértice, no common law, os precedentes são fontes primárias e criadoras do direito, podendo inclusive inovar, sendo prescindível lei que o respalde."

É dentro desse panorâma que se encontra o sistema jurídico brasileiro, influenciado por ambas as tradições jurídicas (o romanismo herdado do direito português com o seu apego à lei escrita, e o controle de constitucionalidade inspirado no modelo do common law americano) ${ }^{13}$, no qual se mostra necessária a adoção de um sistema de precedentes ${ }^{14}$ (positivado no Código de Processo Civil de 2015), cujos objetivos são, conforme apontado por Hermes Zaneti Jr o aumento da racionalidade, igualdade, previsibilidade e efetividade do direito. ${ }^{15}$

\section{DA INTERPRETAÇÃO NO DIREITO}

Passada a primeira parte deste trabalho, impõe-se o tratamento específico da questão referente à interpretação do direito e sua relação com a formação e aplicação dos precedentes judiciais.

\subsection{DO TEXTO À NORMA}

\footnotetext{
${ }^{12}$ CARVALHO, Sabrina Nasser de. Op. Cit. p. 07.

${ }^{13}$ MELLO, Patrícia Perrone Campos. Op. Cit. p. 54/55: “O ordenamento jurídico brasileiro recebeu influências tanto do civil law quanto do common law. Primeiramente, em virtude da colonização portuguesa, recepcionou o sistema romano, adotado por Portugal, e sobre ele firmou suas raízes. A herança lusitana trouxe a concepção da lei como a principal fonte do direito, mas introduziu no Brasil, igualmente os assentos, enunciados judiciais com caráter normativo, que se prestava a dirimir dúvidas sobre a interpretação das normas e a conferir-lhe uniformidade (...)

Em sede de controle de constitucionalidade, o Brasil foi profundamente influenciado pelos Estados Unidos, adotando, a partir da Constituição de 1891, um sistema difuso de judicial review (...)."

${ }^{14}$ ZANETI JR, Hermes. Op. Cit. p. 317: “Ora, em um país com controle difuso de constitucionalidade, para que os tribunais possam cumprir a sua função institucional de aplicar a constituição, é necessário adotar um sistema de precedentes através da regra do stare decisis (que inclui a vinculação argumentativa do próprio tribunal que exarou o precedente)."

${ }^{15}$ Ibid, p. 318.
} 
O exercicio de interpretação dos textos legais, da forma como é atualmente conhecido, passou por um processo evolutivo histórico-social, resultado de estudos de diversos autores que se dedicaram ao tema.

Neste sentido, temos um primeiro momento onde existia equivalência entre o significado de texto e norma (univocidade do texto legal), no qual cabia ao juiz tão somente a declaração do direito posto pelo Parlamento, sem a realização de qualquer tipo de atividade interpretativa, surgindo assim a figura do juiz bouche de la loi ou juge inanimé 16 .

Com o passar dos anos e evolução dos estudos sobre a matéria, em especial com a publicação de Reine Rechtslehre (Teoria Pura do Direito) de Hans Kelsen, The concept of law (O conceito de direito) de Herbert Hart, L'interpretazione della legge (A interpretação da lei) de Giovanni Tarello e das das obras Interpreting Statutes e Interpreting Precedents, decorrentes do encontro do Círculo de Bielefeld ${ }^{17}$, mudou-se a percepção sobre a matéria, passando ao intérprete o papel de atribuir sentido/significado ao texto normativo. ${ }^{18}$

\footnotetext{
${ }^{16}$ MARINONI, Luiz Guilherme. Precedentes Obrigatórios. 5. ed.. São Paulo: Editora Revista dos Tribunais, 2016. p. 46: "Assim, conferiu-se o poder de criar o direito apenas ao legislativo. A prestação judicial deveria se restringir à mera declaração da lei, deixando-se ao executivo a tarefa de executar as decisões judiciais."

${ }^{17}$ Foi uma associação de teóricos jurídicos cujo trabalho deveria ser direcionado a uma análise comparativa da pesquisa metodológica dos fundamentos do direito e sua metodologia através de análise sistemática comparativa e teórica. Sob a direção de Robert SUMMERS e Neil MACCORMICK, e após uma série de reuniões no Centro de Estudos Interdisciplinares em Bielefeld e outras 10 reuniões realizadas em outros lugares, o Círculo de Bielefeld produziu, em 1991, Interpreting Statutes e, em 1997, Interpreting Precedents. "This book on precedent is the second book prepared by a special research group, which calls itself 'The Bielefelder Kreis'. This Book, like the first (on statutory interpretation) seeks to advance understanding of fundamentals of law and its methodology through systematic comparative and theoretical analysis. This research group hels its founding meeting in Helsink, Finland in August of 1983 with Prof. Dr Aulis Aarnio as host. The initiative for the formation of the group was taken by Robert Summers of Cornell Law School after some discussions in Italian Alps during the summer of 1982 with Enrico Pattaro and Aleksander Peczenik. (...) Since 1983, the research group has met once or more annualy in various places in Europe, Britain and the United States, including several times athe the Center for Interdisciplinary Studies at the University of Bielefeld, in Germany."

${ }^{18}$ MITIDIERO, Daniel. Precedentes: da persuasão à vinculação. São Paulo: Editora Revista dos Tribunais, 2017. p. 54. O autor destaca a evolução que a teoria da interpretação apresentou nestas obras, saindo do último capítulo na Teoria Pura do Direito de Hans Kelsen, para objeto central de estudo da teoria do direito. No mesmo sentido: VILLA, Vittorio. A pragmatically oriented theory of legal interpretation. Revus, 12, 2010, p. 02: "Interpretation is at the centre off attention today, much more than in the past, in the most significant trends of contemporary legal theory (for instance, in analytical legal theory and legal hermeneutics) (...) in traditional legal theories, nevertheless, interpretation was considered by and large a "sector topic", though one of decisive importance. If, for instance, we consider the work of Kelsen, certainly the main exponent of the normativist current of legal positivism in the last century, we see that in his main work legal interpretation is discussed in the last chapter (...) Today, instead, some of the most significant works in legal theory are developed precisely as theories of interpretation, and have this focal point as their central theme.
} 
Tal percurso teórico, conforme muito bem sintetizado pelo Prof. Daniel Mitidiero, pode ser observado no movimento que vai da prévia determinação (direito como algo totalmente determinado préviamente à interpretação), à dupla indeterminação do direito (papel da interpretação definir o seu significado), caracterizada pela equivocidade do texto legal e vagueza das normas ${ }^{19}$.

Modernamente, contudo, resta superada a questão da distinção entre texto e norma, não se confundindo mais os seus significados, como consolidado entre autores que se dedicam ao estudo do tema.

Neste sentido, para Hermes Zaneti Júnior, norma é o significado extraído de uma ou mais diposições de lei ou atos normativos considerados como dispositivos, textos ou enunciados normativos ${ }^{20}$. Já Humberto Ávila, norma é o sentido construído a partir da interpretação do texto normativo, o seu resultado ${ }^{21}$. Riccardo Guastini entende que norma é a parte de um texto interpretado ${ }^{22}$. Enquanto para Vittorio Villa, o significado do texto não pertence a ele magicamente, sendo o resultado da atividade interpretativa que tem a norma como resultado. ${ }^{23}$

\subsection{TEORIAS DA INTERPRETAÇÃO JURÍDICA}

Paralelamente a toda a evolução histórica e desenvolvimento doutrinário acima exposto, também foram desenvolvidas diversas teorias

\footnotetext{
${ }^{19}$ MITIDIERO, Daniel. Op. Cit. p. 59: "O direito é indeterminado basicamente por duas razões: os textos em que vazado são equívocos e as normas são vagas. Essa é a razão pela qual se costuma afirmar a "duplice indeterminatezza del diritto". Os textos são equívocos porque ambíguos, complexos. Implicativos, defectivos e por vezes se apresentam em termos exemplificativos ou taxativos. As normas são vagas porque não é possíve"l antever exatamente quais são os fatos que recaem nos seus respectivos âmbitos de incidência."

${ }^{20}$ ZANETI JR, Hermes. Op. Cit. p. 145.

${ }^{21}$ ÁVILA, Humberto. Teoria dos Princípios: da definição à aplicação dos princípios jurídicos. $4^{\mathrm{a}}$ ed. São Paulo: Malheiros, 2005, p. 22/23.

${ }^{22}$ GUASTINI, Riccardo. Das fontes às normas. Trad. Edson Bini. São Paulo: Quartier Latin, 2005, p. 26.

${ }^{23}$ VILLA, Vittorio. Op. Cit. p. 03. No original: From this point of view, it is maintained that meaning does not magically belong to the sentences from wich interpretation starts, but is the result of the interpretative activity that has the norm as its result.
} 
da interpretação jurídica, destacando-se a teoria cognitiva (ou formalista) ${ }^{24}$, a teoria não-cognitiva (cética ou realista) ${ }^{25} \mathrm{e}$ a teoria eclética ${ }^{26}$.

A teoria cognitiva (ou formalista) da interpretação, baseada na idéia de que as palavras possuem significado próprio, encontrou o seu auge no período da dogmática juspositivista do séc. XIX, fundada nas idéias de completude e coerência do sistema jurídico (ausência de lacunas e antinomias), e por isso de que todos os problemas eram solucionados por normas existentes, sem qualquer espaço para a realização de atividade interpretativa pelo juiz. Por todas as suas características, encontrava-se essa teoria diretamente ligada a doutrina da separação de poderes, sujeição do juiz a lei e ao mito da certeza do direito. ${ }^{27}$

A teoria não-cognitiva (cética ou realista) da interpretação, ao contrário, sustenta que a interpretação é atividade de valoração e decisão, e não de conhecimento, dependendo de diversas posturas valorativas do intérprete.

Para essa teoria as palavras não possuem significado próprio, podendo ter uma multiplicidade de significados dados pelo intérprete, razão pela qual as normas jurídicas não preexistem à interpretação, mas ao contrário, são dela resultado, concluindo assim que o sistema jurídico nunca é completo ou coerente, cabendo sempre ao juiz criar direito. ${ }^{28}$

A teoria eclética (ou intermediária) da interpretação busca uma harmonização das teorias anteriores, defendendo que em algumas situações fáceis a interpretação é atividade de conhecimento (teoria cognitiva ou formalista), ocasião em que o intérprete realizará atividade descritiva (descobre o significado do texto), enquanto em outras situações difíceis a interpretação é atividade discricionária (teoria não cognitiva, cética ou realista), na qual o intérprete realizará atividade atributiva (decide o significado do texto).

Apresentadas as teorias acerca da interpretação judicial, entendese não serem elas suficientes, sendo a melhor solução, conforme apresenta Hermes Zaneti $\mathrm{Jr}^{29}$, a adoção de uma teoria cético-moderada (ou realista-

\footnotetext{
${ }^{24}$ ZANETI JR, Hermes. Op. Cit. p. 150. Segundo o autor, filiam-se a essa teoria os juristas formadores da escola processual alemã e italiana.

${ }^{25}$ GUASTINI, Riccardo. Op. Cit. p. 141. Segundo o autor, filiam-se a esse teoria os autores ligados ao realismo jurídico americano, escandinavo e italiano.

${ }^{26}$ ZANETI JR, Hermes. Op. Cit. p. 154. Para o autor, essa teoria é normalmente atribuída às correntes mais avançadas do positivismo normativista.

${ }^{27}$ GUASTINI, Riccardo. Op. Cit. p. 139/140.

${ }^{28}$ Ibid, p. 140/141.

${ }^{29}$ Ibid, p. $154 / 156$.
} 
moderada), na qual a interpretação é realista (texto e norma não se confundem e a própria decisão entre casos fáceis e casos dificeis é já uma escolha), moderada (necessidade de revisão da legislação, literatura jurídica e precedentes aplicáveis ao caso) e responsável (a interpretação é comprometida com a racionalidade e universalização, aplicável a casos análogos futuros que se comprometem a mantê-la estável, coerente e integra).

\subsection{CONCEITO DE INTERPRETAÇÃO JURÍDICA}

Estabelecida a distinção entre texto e norma jurídica, passa-se ao conceito de interpretação jurífica, que segundo nos ensina Riccardo Guastini $^{30}$, não possui significado unívoco entre os juristas, possuindo na realidade cinco significados distintos. ${ }^{31}$

Para o autor, o termo interpretação pode ser entendido, em sentido estrito, naquelas hipóteses quando se busca atribuir significado a um texto obscuro ou contestado. Essa forma de utilização do termo identifica o significado de texto e norma, referindo-se, portanto, a teoria cognitiva (formalista) de interpretação.

Pode também ser utilizado em sentido lato, utilizado em qualquer atribuição de significado normativo, independentemente da sua natureza. Neste significado existe distinção entre texto e norma, referindo-se, portanto, a teoria não cognitiva (cética ou realista) da interpretação.

O termo pode ainda ser utilizado com três outros significados: 1) em sentido muito lato, quando utilizado para referenciar genericamente o trabalho de juristas e outras operações; 2) como forma de tratamento incorreto ou manipulatório; 3) como sinônimo de aplicação.

\footnotetext{
${ }^{30}$ GUASTINI, Riccardo. Op. Cit. p. 134/139.

${ }^{31}$ No mesmo sentido. ALVES, H. N.; BUSTAMANTE, T. R. "A interpretação literal no direito tributário brasileiro: uma proposta de interpretação para o artigo 111 do CTN. In: ÁVILA, Humberto. Fundamentos de Direito Tributário. Madrid; Barcelona; Buenos Aires; São Paulo: Marcial Pons, 2012. P. 07/08.: "A exemplo do conceito de "significado literal", também o conceito de "intepretação" não é unívoco entre os juristas. Sem embargo, pode-se concordar com Wróblewski quando este distingue três sentidos principais do termo "interpretação" segundo seu grau de abstração: um sentido muito amplo, eminentemente hermenêutico, segundo o qual interpretar equivale a "compreender qualquer objeto cultural"; um sentido amplo, de caráter semântico, para o qual a interpretação direciona-se ao "entendimento da linguagem", e, no caso específico de discursos normativos, à "atribuição de significados a documentos normativos"; e, finalmente, um sentido especificamente jurídico, para o qual a interpretação ocorre quanto há dúvida sobre o "correto entendimento de um texto em seu significado direto [direct meaning]", sendo desnecessária, portanto, em "situações de isomorfia".
} 
Feitos os devidos esclarecimentos, e fundamentado na filosofia analítica do direito da Escola de Gênova apresentado por Carlos Frederico Bastos Pereira e Hermes Zaneti Júnior ${ }^{32}$, cujos principais expoentes são Giovanni Tarello, Riccardo Guastine e Pierluigi Chiassoni, pode-se dizer que interpretar é o ato pelo qual se descreve (identifica um significado do texto normativo), adscreve (identifica dois ou mais resultados no texto normativo, decidindo por um deles) ou cria (identifica dois ou mais resultados no texto normativo, decidindo por um novo) significados ao texto/ enunciado normativo, da qual será extraída a ratio decidendi formadora da normal geral e futura do precedente judicial.

\section{OS DEVERES DE UNIFORMIZAÇÃO, ESTABILIDADE, INTEGRIDADE E COERÊNCIA PREVISTOS NO ART. 926 DO CÓDIGO DE PROCESSO CIVIL}

Durante a vigência do código de processo civil de 1973, inexistiam mecanismos eficazes para o resguardo da uniformidade das decisões judiciais, o que acabava, muitas vezes, gerando uma situação de contradição entre os julgados proferidos.

Com o novo diploma processual, acabou incorporado como um dos principais pilares do ordenamento jurídico brasileiro um sistema de precedentes judiciais obrigatórios ${ }^{33}$, expresso através de um imperativo

\footnotetext{
${ }^{32}$ PEREIRA, Carlos frederico Bastos; ZANETI JUNIOR, Hermes. Teoria da Decisão Judicial no Código De Processo Civil: Uma Ponte entre Hermenêutica e Analítica?. Revista de Processo, v. 259, 2016. P. 31.

${ }^{33}$ CAMARGO, Margarida Maria Lacombe; LEGALE, Siddharta. O microssistema de precedentes no Código de Processo Civil de 2015. In: VIEIRA, José Ribas; LACOMBE, Margarida; LEGALE, Siddharta. Jurisdição constitucional e direito constitucional internacional. Belo Horizonte: Fórum, 2016. p. 16). Os autores concordam com a afirmação da existência de um microssistema de precedentes: "Esses artigos constituem dispositivos centrais de um "microssistema de precedentes", de "microssistema de litigiosidade repetitiva" ou de um "núcleo do dogmático modelo de precedentes brasileiro". Originalmente, o Projeto N. ${ }^{\circ} 166$ de 2010 não previa um capítulo específico dedicado aos precedentes. No substitutivo na Câmara dos Deputados, chegou-se a prever um capítulo específico dedicado ao tema dos precedentes: o Capítulo XV, com 18 dispositivos a partir dos art. 520.

O capítulo específico foi suprimido na redação final do CPC vigente. Ainda assim, há cinco dipositivos presentes ao longo do seu corpo, empregando expressamente a palavra precedentes. Esses dispositivos, em uma interpretação sistemática, constituem uma espécie de savepoints do espólio do capítulo de precedentes que resistiram à supressão pelo Senado Federal, introduzido pelo substitutivo da Câmara dos Deputados. São eles: o art. 489 (fundamentação das decisões), o art. 926, §2 (atenção as circunstâncias fáticas), o art. 927 (publicidade dos temas na internet); art. 988 (cabimento de reclamação para cumprir precedente); e art. 1042 (distinguishing do sobrestado ao paradigma).
} 
categórico previsto no art. 926, no qual determinou-se aos tribunais o dever de uniformizar sua jurisprudência, mantendo-a estável, integra e coerente. ${ }^{34}$

\subsection{DEVER DE UNIFORMIZAÇÃO}

O primeiro dos imperativos categóricos impostos pelo art. 926 do Código de Processo Civil é o dever dos tribunais de uniformizar a sua jurisprudência.

Quer esse dever significar, segundo lição de Fredie Didier Jr. ${ }^{35}$, que existindo divergência interna em determinado tribunal, cabe a ele resolvê-la, uniformizando o seu entendimento sobre o assunto, preferencialmente sumulando a sua jurisprudência dominante. ${ }^{36}$

\subsection{DEVER DE ESTABILIDADE}

O segundo imperativo categórico imposto pelo art. 926 do Código de Processo Civil trata do dever de estabilidade (dever de manter a jurisprudência estável).

Por meio desse dever, em atenção a regra do stare decisis, devem os precedentes formados ser seguidos ${ }^{37}$, seja pela própria corte que proferiu

\footnotetext{
Uma leitura sistemática dos princípios da parte geral, dos recursos repetitivos e dos dispositivos indicados revela que, a despeito de se ter suprimido um capítulo específico, há sim um "microssistema de precedentes", que introduz uma lógica jurídica própria paralela ao tradicional sistema de recursos do Código. De um lado, abre-se um maior espaço para a interpretação constitucional pela ponderação ou integridade (microssistema de precedentes) e, de outro, uma interpretação jurídica mais tradicional, orientada pelos métodos clássicos literal, sistemático, histórico e teleológico (sistema recursal)"

${ }^{34}$ Art. 926. Os tribunais devem uniformizar sua jurisprudência e mantê-la estável, íntegra e coerente.

${ }^{35}$ DIDIER JR., Fredie. Sistema Brasileiro de Precedentes Judiciais Obrigatórios e os Deveres Institucionais dos Tribunais: uniformidade, estabilidade, integridade e coerência da jurisprudência. In: DIDIER JR., Fredie; CUNHA, Leornardo Carneiro da; MACEDO, Lucas Buril de; ATAIDE JR., Jaldemiro R. de. Coleção Grandes Temas do Novo CPC: Precedentes. Salvador: JusPODIVM, 2015, p. 384.

${ }^{36}$ Art. $926(\ldots)$

$\S 1^{\circ} \mathrm{Na}$ forma estabelecida e segundo os pressupostos fixados no regimento interno, os tribunais editarão enunciados de súmula correspondentes a sua jurisprudência dominante.

$\S 2^{\circ}$ Ao editar enunciados de súmula, os tribunais devem ater-se às circunstâncias fáticas dos precedentes que motivaram a sua criação.

${ }^{37}$ ZANETI JR, Hermes. Op. Cit. p. 337: "O princípio do stare decisis assegura um predicado - a estabilidade - para as decisões do tribunal, sendo especialmente voltado para as próprias cortes que estabelecem o precedente, forçando o cotejo racional das decisões dos casos-precedentes com os casosatuais.
} 
a decisão (vinculação horizontal) ou por aquelas hierarquicamente inferiores (vinculatividade vertical), devendo toda e qualquer alteração de posicionamento (superação ou overrruling) ${ }^{38}$, sob pena de ofensa ao princípio da segurança jurídica, ser devidamente justificada. ${ }^{39}$

\subsection{DEVERES DE COERÊNCIA E INTEGRIDADE}

O Código de Processo Civil também inovou ao disciplinar no $\mathrm{ca}$ put do seu art. 926, com o objetivo de evitar a multiplicação de decisões padronizadas, dois conceitos altamente difundidos na teoria geral do direito contemporânea, que são os termos coerência e integridade.

Neste sentido, em que pese existir na doutrina diferentes autores e orientações filosóficas tratando do tema ${ }^{40}$, interpretando-os inclusive como equivalentes, necessário que se destaque que não o são. Trata o caput do referido artigo de deveres distintos.

Da mesma forma, segundo afirmam Margarida Maria Lacombe Camargo e Siddharta Legale ${ }^{41}$, necessário que sejam os conceitos interpretados de forma convergente ${ }^{42}$, pois sozinhos mostram-se insuficientes.

Os precedente judiciais, por sua vez, identificam-se mais com o processo seguido pelos tribunais como resultado do stare decisis, atingindo igualmente os tribunais e juízes de hierarquia inferior, os quais devem aplicar o conteúdo dos precedentes independentemente de suas razões.

A doutrina fala aqui em uma distinção entre hierarquia institucional vertical e hierarquia institucional horizontal. A primeira consolida-se na aplicação dos precedentes das Cortes Supremas, não significando que um juiz de tribunal é mais importante que um juiz de piso, mas que as funções exercidas são distintas. A segunda, por outro lado, representa a vinculação da própria corte entre os juízes do passado (caso-precedente) e os juízes do presente (caso-atual), que devem seguir o princípio do stare decisis." ${ }^{38}$ Ibid, p. 340/341: "As Cortes Supremas podem, portanto, mesmo diante da regra do stare decisis, superar o precedente (overruling) ou entender que se trata de um caso diverso, prescrevendo uma regra diferente (distinguishing), desde que considerem ser esta a melhor solução de direito. Tal tarefa revelase eminentemente interpretativa e irredutivelmente confiada às Cortes."

${ }^{39}$ Enunciado 453 FPPC. (arts. 926 e 1.022, parágrafo único, I) A estabilidade a que se refere o caput do art. 926 consiste no dever de os tribunais observarem os próprios precedentes. (Grupo: Precedentes, IRDR, Recursos Repetitivos e Assunção de Competência

${ }^{40}$ DIDIER Jr, Fredir. Op. Cit. p. 387/388. O autor destaca a referida confusão nas notas de rodapé $11 / 13$.

${ }^{41}$ CAMARGO, Margarida Maria Lacombe; LEGALE, Siddharta. Op. Cit. p. 20.

${ }^{42}$ COPETTI NETO, Alfredo; ZANETI JUNIOR, Hermes. Os deveres de coerência e integridade: a mesma face da medalha? A convergência de conteúdo entre Dworkin e MacCormick na teoria dos precedentes judiciais normativos formalmente vinculantes. Derecho y Cambio Social, v. 46, p. 16: “ Portanto, para corretamente compreender os deveres de coerência/consistência (em sentido estrito, dever de não contradição) e integridade/coerência (coerência normativa em sentido amplo), eles devem ser considerados como pares conceituais. Esta nos parece ser a melhor solução para o problema da integridade/coerência no NCPC. Justamente por isso, defendemos a convergência - sem identidade 


\subsubsection{DEVER DE COERÊNCIA}

O terceiro dos imperativos impostos pelo caput art. 926 do Código de Processo Civil trata do dever de coerência (coerência em sentido estrito, coerência-consistência), que segundo observado por Alfredo Copetti Neto e Hermes Zaneti $\mathrm{Jr}^{43}$, é o dever de não contradição entre as decisões judiciais (passadas e futuras), como corolário da segurança jurídica e proteção da confiança, evitando-se assim uma loteria judicial. ${ }^{44}$

\subsubsection{DEVER DE INTEGRIDADE ${ }^{45}$}

O último dos imperativos categóricos impostos pelo caput do art. 926 do Código de Processo Civil trata do dever de integridade (coerência em sentido amplo, integridade-coerência), dever esse diretamente ligado ao postulado da unidade do direito. ${ }^{46}$

Neste sentido, segundo lição de Fredir Didier $\mathrm{Jr}^{47}$, a observação do dever de integridade exige dos tribunais a adoção de certas posturas: decisão conforme o direito e observando toda a sua complexidade; decisão respeitando a Constituição como fundamento normativo de todas as normas jurídicas; compreensão do direito como sistema de normas;

\footnotetext{
absoluta - entre as teorias de Dworkin e MacCormick, entre os termos integridade e coerência em sentido amplo, convergência já admitida pela doutrina brasileira e internacional."

${ }^{43}$ Ibid, p. 17.

${ }^{44}$ Enunciado 454 FPPC. (arts. 926 e 1.022, parágrafo único, I) Uma das dimensões da coerência a que se refere o caput do art. 926 consiste em os tribunais não ignorarem seus próprios precedentes (dever de autorreferência). (Grupo: Precedentes, IRDR, Recursos Repetitivos e Assunção de Competência) Enunciado 455 FPPC. (art. 926) Uma das dimensões do dever de coerência significa o dever de não contradição, ou seja, o dever de os tribunais não decidirem casos análogos contrariamente às decisões anteriores, salvo distinção ou superação. (Grupo: Precedentes, IRDR, Recursos Repetitivos e Assunção de Competência)

${ }^{45}$ CAMARGO, Margarida Maria Lacombe; LEGALE, Siddharta. Op. Cit. p. 22/23. Segundo os autores, o termo é inspirado na doutrina de Ronald Dworkin: "A palavra integridade presente no art. 926 inspira-se claramente no pensamento de Ronald Dworkin. Segundo Lênio Streck, a integridade com base no pensamento do autor norte-americano foi introduzida no CPC de 2015 por sugestão de uma "emenda"dele próprio, com apoio dos Profs. Fredie Didier e Luiz Henrique Volpe, em razão da atenção dispensada a ele pelo relator do projeto na Câmara, o Deputado Paulo Teixeira."

${ }^{46}$ Enunciado 456 FPPC. (art. 926) Uma das dimensões do dever de integridade consiste em os tribunais decidirem em conformidade com a unidade do ordenamento jurídico. (Grupo: Precedentes, IRDR, Recursos Repetitivos e Assunção de competência)

Enunciado 457 FPPC. (art. 926) Uma das dimensões do dever de integridade previsto no caput do art. 926 consiste na observância das técnicas de distinção e superação dos precedentes, sempre que necessário para adequar esse entendimento à interpretação contemporânea do ordenamento jurídico. (Grupo: Precedentes, IRDR, Recursos Repetitivos e Assunção de competência).

${ }^{47}$ DIDIER JR, Fredie. Op. Cit. p. 396/398.
} 
observância da relação entre direito material e direito processual; enfrentamento de todos os argumentos favoráveis e contrários para a formação de um precedente.

\section{CONCLUSÃO}

Tempo e prática levaram os intérpretes do direito a conclusão de que a simples aplicação literal da lei não é suficiente para que a sociedade acompanhe as mudanças sociais por que passa, cabendo ao intérprete, no caso concreto, enfrentar e resolver os problemas que lhe são apresentados.

Dentro do desenvolvimento deste processo é que surge a figura dos precedentes judicais, ainda como um primeiro julgado, resultado da interpretação do texto legal pelo juiz, e do qual se extrairá a sua ratio decidendi, que virá a ser a norma jurídica geral a ser adotada para os casos futuros.

Visando regulamentar toda essa situação foi que o legislador, ao elaborar e promulgar o novo Código de Processo Civil, instituiu um sistema de precedentes judiciais no sistema jurídico brasileiro, estabelecendo deveres capazes de possibilitar a sua construção e manutenção através da regra do stare decisis prevista no art. 926.

\section{REFERÊNCIAS}

ALVES, H. N.; BUSTAMANTE, T. R. “A interpretação literal no direito tributário brasileiro: uma proposta de interpretação para o artigo 111 do CTN. In: ÁVILA, Humberto. Fundamentos de Direito Tributário. Madrid; Barcelona; Buenos Aires; São Paulo: Marcial Pons, 2012.

ARAÚJO, Maria Clara Queiroz. Decisões vinculantes contraditórias à luz dos deveres de estabilidade, coerência e integridade do CPC/2015. In: II Congresso de Processo Civil Internacional, v. 02, 2017, Vitória, ES. Anais. Vitória: UFES, 2017. Disponível em: http://periodicos.ufes.br/processocivilinternacional/issue/view/860.

ÁVILA, Humberto. Teoria dos Princípios: da definição à aplicação dos princípios jurídicos. $4^{\mathrm{a}}$ ed. São Paulo: Malheiros, 2005.

Ciência do Direito Tributário e Discussão Crítica. Revista de Direito Tributário Atual. São Paulo, no 32, 2014. p. 159/197.

BUSTAMANTE, Thomas da Rosa. Teoria do Precedente Judicial: A justificação e a aplicação de regras jurisprudenciais. São Paulo: Noeses, 2012. 
CAMARGO, Margarida Maria Lacombe; LEGALE, Siddharta. O microssistema de precedentes no Código de Processo Civil de 2015. In: VIEIRA, José Ribas; LACOMBE, Margarida; LEGALE, Siddharta. Jurisdição constitucional e direito constitucional internacional. Belo Horizonte: Fórum, 2016. p. 15-36. ISBN 978-85-450-0196-6. Disponível em: <h p://www.bidforum.com.br〉.

CARVALHO, Sabrina Nasser de. Decisões paradigmáticas e dever de fundamentação: técnica para formação e aplicação dos precedentes. Revista de Processo. São Paulo, Revista dos Tribunais, vol. 40, n. 249, 2015.

COELHO, Helena Beatriz Cesarino Mendes. Interpretação Jurídica: algumas teorias, segundo Riccardo Guastini, e sua aplicação a um caso concreto. RPGE. Porto Alegre, v. 30, nº 64, 2006, p. $95 / 114$.

COPETTI NETO, Alfredo; ZANETI JUNIOR, Hermes. Os deveres de coerência e integridade: a mesma face da medalha? A convergência de conteúdo entre Dworkin e MacCormick na teoria dos precedentes judiciais normativos formalmente vinculantes. Derecho y Cambio Social, v. 46, p. 1-21, 2016.

DIDIER JR., Fredie. Sistema Brasileiro de Precedentes Judiciais Obrigatórios e os Deveres Institucionais dos Tribunais: uniformidade, estabilidade, integridade e coerência da jurisprudência. In: DIDIER JR., Fredie; CUNHA, Leornardo Carneiro da; MACEDO, Lucas Buril de; ATAIDE JR., Jaldemiro R. de. Coleção Grandes Temas do Novo CPC: Precedentes. Salvador: JusPODIVM, 2015, p. $383 / 398$.

GUASTINI, Riccardo. Das fontes às normas. Trad. Edson Bini. São Paulo: Quartier Latin, 2005.

Interpretación y Construcción Jurídica. ISONOMÍA. nº 43, p. 11/48, 2015;

HART, H. L. A. O conceito de direito. Trad. Antônio de Oliveira Sette-Câmara. São Paulo: Editora WMF Martins Fontes, 2009.

KELSEN, Hans. Teoria pura do direito: introdução à problemática científica do direito. Trad. J. Cretella Jr. E Agnes Cretella. 3. ed.. São Paulo: Editora Revista dos Tribunais, 2003.

LOPES FILHO, Juraci Mourão. Os precedentes judiciais no constitucionalismo brasileiro contemporâneo. 2. ed.. Salvador: Editora JusPodivm, 2016.

MACCORMICK, Neil; SUMMERS, Robert. Interpreting Precedents. A Comparative Study. Aldershot: Dartmouth, 1997.

Retórica e o estado de direito. Trad. de Conrado Hubner Mendes. Rio de Janeiro: Elsevier, 2008. p. 247/307.

MARINONI, Luiz Guilherme. Precedentes Obrigatórios. 5. ed.. São Paulo: Editora Revista dos Tribunais, 2016.

MARTINS, Argemiro; ROESLER, Cláudia; JESUS, Ricardo. A noção de coerência na teoria da argumentação jurídica de Neil Maccormick. Novos Estudos Jurídicos, v. 16, nº 2, p. 207/221, 2011. 
Julgamento nas cortes supremas: precedentes e decisão do recurso diante do novo CPC. 2. ed.. São Paulo: Editora Revista dos Tribunais, 2017.

MELLO, Cláudio Ari. Interpretação jurídica e dever de fundamentação das decisões judiciais no novo código de processo civil. Revista de Processo, v. 255, 2016.

MELLO, Patrícia Perrone Campos. Precedentes: o desenvolvimento judicial do direito no constitucionalismo contemporâneo. Rio de Janeiro: Editora Renovar, 2008.

MITIDIERO, Daniel. Cortes Superiores e Cortes Supremas: do controle à interpretação da jurisprudência ao precedente. São Paulo: Revista dos Tribunais, 2013.

Fundamentação e Precedente: dois discursos a partir da decisão judicial. Revista de Processo. São Paulo, no 206, 2012. p. 61/78.

Precedentes: da persuasão à vinculação. São Paulo: Editora Revista dos Tribunais, 2017.

PEREIRA, Carlos frederico Bastos; ZANETI JUNIOR, Hermes. Teoria da Decisão Judicial no Código De Processo Civil: Uma Ponte entre Hermenêutica e Analítica?. Revista de Processo, v. 259, p. 21-53, 2016.

TARELLO, Giovanni. La interpretación de la ley. Trad. Diego Dei Veicchi. Lima: Palestra Editores, 2018.

TARUFFO, Michele. Precedente e jurisprudência. Trad. Chiara de Teffé. Civilistica.com. Rio de Janeiro, a. 3, n. 2, jul.-dez./2014. Disponível em: http://civilistica.com/precedente-e-jurisprudencia/. Data de acesso. 18/03/2019.

VILLA, Vittorio. A pragmatically oriented theory of legal interpretation. Revus, 12, 2010.

ZANETI JR., Hermes. O valor vinculante dos Precedentes: teoria dos precedentes normativos formalmente vinculantes. $3^{\text {a }}$ ed. Salvador: JusPODIVM, 2017. 